\title{
Prioritizing Critical Success Factors for Six Sigma Implementation Using Interpretive Structural Modeling
}

\author{
Hisham Alidrisi \\ Department of Industrial Engineering, King Abdulaziz University, Jeddah, Saudi Arabia \\ Email: $\underline{\text { hmalidrisi@kau.edu.sa }}$ \\ Received 15 October 2014; revised 18 November 2014; accepted 27 November 2014 \\ Copyright (C) 2014 by author and Scientific Research Publishing Inc. \\ This work is licensed under the Creative Commons Attribution International License (CC BY). \\ http://creativecommons.org/licenses/by/4.0/

(c) (i) Open Access

\begin{abstract}
The purpose of this paper is to provide a practical approach for prioritizing the most practiced Critical Success Factors (CSFs) for six sigma implementation. The most commonly accepted CSFs for six sigma were identified from the literature. Then, the interactions among twelve CSFs have been studied using one of the mathematical/soft-operational research tools, that is, the Interpretative Structural Modeling (ISM). The developed model was illustrated using a case study selected from an automotive service industry. The findings implied that almost all of the CSFs are classified as linkage variables. The developed model provides a road map that assists practitioners to understand the process through which six sigma is practiced in a certain enterprise. Although the studied case was selected from the automotive service industry, the outcome of the proposed ISM model supported the results of the previous empirical studies in a sense that all factors for six sigma implementation were in fact critical (i.e. none of them was located within the autonomous category).
\end{abstract}

\section{Keywords}

Critical Success Factors, Six Sigma, Interpretative Structural Modeling, Prioritization, Automotive Service Industry

\section{Introduction}

Without doubt, there is no one single way for six sigma implementation, and consequently, six sigma can be conceptually defined in different ways. Indeed, due to the fact that the concept of six sigma covers a wide range of problem solving tools that aim to change the culture in an optimal manner, it is quite difficult to have a 
straightforward definition for it [1]. Though, it can be said that six sigma is a target driven methodology through which an organization can achieve superior improvement. Snee [2] defined six sigma as a methodology that aims to spot and eliminate faults within the processes by concentrating on features that are considered significant by customers. Such an improvement can be attained swiftly as a result of creating and applying a mixture of various statistical methods as well as respected mathematical techniques [1]. This way of thinking resulted in achieving considerable aspects of performance improvement in many well-established companies [2]-[5].

The concept of six sigma was introduced firstly by Motorola in the early 1980s [6], followed by numerous successful stories within manufacturing as well as service industries. Nowadays, there is no doubt that successful implementation of six sigma methodology becomes sort of a competitive advantage as millions of dollars can be saved accordingly. Antony [5] stated that Firms that have implemented six sigma successfully concentrated on "increasing the wealth of the shareholders by improving bottom-line results and achieving high quality products and services". He pointed out four dimensions that differentiate six sigma from other quality management models:

- Linking the achievement to financial measures such as Return on investment (ROI).

- Incorporating the soft elements of system improvement (such as culture, cooperation and all other elements related directly to human's behavior) with all aspects of process management (the hard elements).

- Combining the statistical (or any quantitative) methods and other (soft) techniques in a chronological way under the umbrella of the five famous steps of implementing six sigma (Define-Measure-Analyze-Improve-Control).

- Creation of solid base of teamwork infrastructure through identifying different scopes and hierarchal levels for six sigma project management (Yellow Belts, Green Belts, Black Belts,... etc.).

Therefore, it is not surprising that researchers as well as practitioners are in agreement regarding six sigma's benefits. However, the issue of developing a generic framework for six sigma implementation has always been investigated in the literature [7]-[13]. Though, and to best of the author's knowledge, neither of these attempts has studied the interaction among these factors in a sense that they have not been classified according to their priorities within the implementation process itself. From a practical point of view, this is important and in need to be addressed to provide the practitioner an understandable picture for these factors in order to, for instance, decide which element should be implemented firstly.

This paper argues that a further investigation should be conducted through developing an Interpretive Structural Modeling (ISM) to understand the relationships among these factors. Put simply, the aim of this paper is to provide a practical approach to prioritize the most practiced Critical Success Factors (CSFs) of implementing six sigma. The most commonly accepted CSFs of six sigma implementation are identified from the literature. Then, the interactions among twelve CSFs have been studied using the methodology of ISM. The developed model is illustrated using a case study selected from an automotive service industry.

\section{Literature Review}

\subsection{CSFs for Six Sigma Implementation}

The CRFs represent the factors that are considered "critical" to the success of any firm and, consequently, failing in attaining the relevant goals of these factors implies disaster failing of the entire firm [14]. In regard to the field of six sigma, Handeron and Evans [7] considered six sigma as a latest Total Quality Management (TQM) fashion by which firms can attain performance excellance. They reviewed all key philosophies behind the concept of six sigma, its advantages, and the relevant methods/techniques for its execution and application in order to benchmark General Electric's practices of six sigma. They concluded that the CSFs for six sigma implementation are:

- Upper management support and involvement.

- Organizational infrastructure.

- Training.

- Tools.

- Links to human resources-based actions.

Afterward, Antony and Banuelas [8] presented what they called "the key ingredients" for launching and implementing six sigma in UK's manufacturing and service industries. These key ingredients have been commonly referred as CSFs for six sigma implementation. These CSFs are: 
- Management involvement and commitment.

- Understanding tools and methods for six sigma.

- Linking six sigma to business strategy.

- Linking six sigma to customer.

- Project selection and tracking.

- Organizational infrastructure.

- Cultural change.

- Project management skills.

- Linking six sigma to suppliers.

- Training.

- Linking six sigma to human resources.

The factor of "Communication" has also been considered by Coronado and Anthony [9] as an additional dimension to the CSFs. Starbird [10] considered six sigma as a part of the process of managing the system within the journey of reaching business excellence. Three elements were identified by Stabird as main keys to successful implementation of six sigma. These elements are:

- Initiating process management.

- Determining performance through reporting.

- Integrating supports for projects by determining the needed updates during staff meetings.

After that, Johnson and Swisher [11] pointed out four practical guidelines to ensure successful application of six sigma projects as:

- Continued and noticeable managerial commitment.

- Ongoing education and training for executives and team members.

- Outlining clear expectations and electing project leaders carefully for leadership capabilities.

- Careful selection of significant projects that have strategic potential.

About eight years ago, Kwak and Anbari [12] critically reviewed the literature of six sigma and discussed the issue with a number of experts within the field of six sigma. They concluded that the key factors for six sigma implementation are:

- Managerial commitment and involvement.

- Skills for managing and selecting projects.

- Motivation for cultural change.

- Training and ongoing education for six sigma.

Recently, Brun [13] suggested the same list of the CSFs that have been developed by Coronado and Anthony [9], with small modifications. Brun expanded the factor of "Trainin” to be "Education and Training”, as identified by Kwak and Anbari [12]. Brun has also expanded the factor of "Organizational infrastructure” to be "Organizational infrastructure and culture” as reported in one of the related study [15]. Brun’s list of twelve CSFs [13], as shown in Table 1, is employed for the purpose of this study.

Table 1. CSFs for six sigma (source: Brun [13]).

\begin{tabular}{cc}
\hline CSFs for six sigma & Acronym \\
\hline Management involvement and commitment & CSF1 \\
Cultural change & CSF2 \\
Communication & CSF3 \\
Organizational infrastructure and culture & CSF4 \\
Education and training & CSF5 \\
Linking six sigma to business strategy & CSF6 \\
Linking six sigma to customer & CSF7 \\
Linking six sigma to human resources & CSF8 \\
Linking six sigma to suppliers & CSF9 \\
Understanding tools and techniques within six sigma & CSF10 \\
Project management skills & CSF11 \\
Project prioritization and selection & CSF12 \\
\hline
\end{tabular}




\subsection{The ISM Method}

ISM is a well-known approach that facilitates visualizing complex relationships among set of factors in order to enable the decision maker to understand the complex situation [16]. The mathematical base of ISM was introduced in different works [17]-[19], while the philosophical side has been introduced by Warfield [20]. ISM is also commonly known as one of the soft operational research techniques [21]-[23]. ISM helps individuals, usually involved as a group of experts, to discover the relationships among factors, elements, barriers or any set of entities [16] [24]-[27]. Specifically, the method of ISM is commonly applied to solve the issue of supplier selection [24] [28], prioritizing set of enablers or success factors [29]-[31], and ranking set of barriers [27] [32]. The most recent applications of ISM covered a broad and various areas of Engineering and management such as energy management [33], Supply Chain Management (SCM) [34], green SCM [35]-[37], entrepreneurship [32], Human Resource Management (HRM) [38], and performance evaluation [31] [39].

Within the field of quality management, Mehta, Verma, and Seth used the Delphi method to identify the principles of TQM in engineering education [40]. Then, they implemented the ISM approach in order to develop a contextual relationship among different TQM principles. Accordingly, this helped them in prioritizing the actions that should be considered within the process of improving engineering education. Similarly, the interactions among various TQM enablers have been studied by Singh [30] in order to obtain an accurate picture of the Indian aviation sector. The application of ISM in such a sector helped in initiating a road map through which a better understanding of how TQM works was obtained. Soti, Shankar, and Kaushal studied the enablers of six sigma using ISM [29], which may be considered similar to the objective of this study, however, they clearly differentiated between enablers and success factors of six sigma saying that:

Critical success factors assure successful installation, functioning and sustainability of six sigma system; whereas, enablers assure successful installation of a six sigma system. Therefore, enablers are defined as a

subset of critical success factors...there is a very thin line between the general term success factors and specific term enablers, but these are defiantly different in definition and application.

Such a difference encouraged the author to apply the method of ISM in order to investigate the CSFs of six sigma within the automotive service industry, in Saudi Arabia, as illustrated in this paper.

\section{The Application of ISM}

According to the previous applications of ISM [24] [27] [28], the steps of implementing ISM can be summarized in the following points:

1) Defining a list of elements or factors that are going to be investigated. These factors can be identified through surveys, experts opinions, or reviewed literature (i.e. as shown in this paper).

2) Setting up contextual relationships among the defined factors.

3) Developing a Structural Self-interaction Matrix (SSIM) as a reflection of the pair-wise contextual relationships between the factors.

4) Forming the reachibility matrix from the developed SSIM. Then, the reachability matrix is checked for transitivity. Transitivity of the contextual relation within ISM implies respecting the assumption that if factor A leads to factor B, and factor B leads to factor C, then consequently, factor A leads to factor C.

5) Dividing the developed reachability matrix into different levels.

6) Drawing a directed graph (diagraph) according to the rechability matrix.

7) Converting the developed diagraph into an ISM-based model by replacing nodes numbers with factors names. Note that this step can be avoided if factors names are used directly/initially.

8) Reviewing the model for further modifications or clarifications.

As discussed above, the literature of the CSFs for six sigma implementation is critically reviewed to obtain the most commonly accepted CSFs, with respect to the recent update in the literature. Accordingly, a list of twelve CRFs for six sigma has been identified as shown in Table 1. The case of one of the most successful company in the field of automotive service industry in Saudi Arabia was investigated. Experts' opinions have been employed as inputs to conduct the application of ISM. In order to identify the contextual relationships among the CSFs as shown in Table 2, four symbols are used by the experts to signify the direction of the relationships among the twelve CSFs:

- V: if CSF i leads to successful implementation of CSF j.

- A: if CSF j leads to successful implementation of CSF i. 
Table 2. The structural self-interaction matrix (SSIM).

\begin{tabular}{|c|c|c|c|c|c|c|c|c|c|c|c|}
\hline CSFs & CSF12 & CSF11 & CSF10 & CSF9 & CSF8 & CSF7 & CSF6 & CSF5 & CSF4 & CSF3 & CSF2 \\
\hline CSF1 & V & $\mathrm{O}$ & $\mathrm{O}$ & $\mathrm{X}$ & $\mathrm{V}$ & $\mathrm{X}$ & $\mathrm{V}$ & $\mathrm{X}$ & V & $\mathrm{X}$ & V \\
\hline CSF2 & A & $\mathrm{O}$ & A & A & A & A & A & A & $\mathrm{O}$ & $\mathrm{X}$ & \\
\hline CSF3 & $\mathrm{X}$ & A & A & $\mathrm{X}$ & $\mathrm{X}$ & $\mathrm{X}$ & V & A & V & & \\
\hline CSF4 & A & $\mathrm{O}$ & $\mathrm{O}$ & A & A & A & A & $\mathrm{O}$ & & & \\
\hline CSF5 & $\mathrm{O}$ & V & V & A & A & A & A & & & & \\
\hline CSF6 & $\mathrm{X}$ & V & V & $\mathrm{X}$ & $\mathrm{X}$ & $\mathrm{X}$ & & & & & \\
\hline CSF7 & $\mathrm{X}$ & V & V & $\mathrm{X}$ & $\mathrm{X}$ & & & & & & \\
\hline CSF8 & A & V & $\mathrm{X}$ & $\mathrm{X}$ & & & & & & & \\
\hline CSF9 & $\mathrm{X}$ & V & $\mathrm{X}$ & & & & & & & & \\
\hline CSF10 & V & V & & & & & & & & & \\
\hline CSF11 & $\mathrm{O}$ & & & & & & & & & & \\
\hline CSF12 & & & & & & & & & & & \\
\hline
\end{tabular}

- $\mathrm{X}$ : if both, CSF i and CSF j, leads to successful implementation of each other.

- $\mathrm{O}$ : if there is no relation between CSF $\mathrm{i}$ and CSF $\mathrm{j}$.

The next step is to convert the SSIM into a binary matrix, known as the initial reachability matrix as shown in Table 3. The initial reachability matrix is developed according to following substitution rules:

- If the (i, j) input in the SSIM is V, the (i, j) input in the reachability matrix becomes 1 and the (j, i) input becomes 0 .

- If the (i, j) input in the SSIM is $A$, the (i, j) input in the reachability matrix becomes 0 and the (j, i) input becomes 1 .

- If the (i, j) input in the SSIM is X, the (i, j) input in the reachability matrix becomes 1 and the (j, i) input also becomes 1 .

If the $(i, j)$ input in the SSIM is $\mathrm{O}$, the $(i, j)$ input in the reachability matrix becomes 0 and the (j, i) input also becomes 0 .

Then, the process of transitivity check is executed through considering the assumption that if CSF1 leads to successful implementation of CSF2, and CSF2 leads to successful implementation of CSF3, then CSF1 leads to successful implementation of CSF3. Consequently, some inputs in the initial reachability matrix are converted from 0 to 1 in the final reachability matrix. The converted inputs are labled by “*” as shown in the final reachability matrix (Table 4).

The next step is to classify the CSFs in different levels. In this step, three terms should be clearly explained: reachability set, antecedent set, and intersection. As shown in Table 5, the reachability set for each CSF(i) represents the CSF (i) itself and all other CSFs that are influenced directly or indirectly (i.e. after the process of transitivity check) by CSF (i). For example, the reachability set for CSF1 contains all twelve CSFs (1, 2, 3,... 12), which implies that CSF1 has an influence to all twelve CSFs (note that two out of the twelve are influenced indirectly as shown in Table 4: CSF10 and CSF11). This justifies that all inputs for the CSF1's row in Table 4 $=1$. In contrast, the reachability set for CSF4 contains the factor itself [Only CSF4], which indicates that CSF4 has no influence to any of the remaining eleven CSFs. This justifies all 0 entries for the CSF4 in Table 4.

The antecedent set is the reversal of the reachability set in a sense that antecedent set includes all CSFs that have a direct or indirect influence on a certain CSF (i), including CSF (i) itself. For instance, as CSF4 is influenced by all CSFs, all twelve CSFs are considered within the antecedent set for CSF4. It can also be seen that all input entries for the column corresponding to CSF4 in Table $4=1$. The same procedure is applied to all CSFs to create the reachability set and the antecedent set for each CSF.

It is important to note that the column of intersection for each CSF (i) contains any CSF that is existing in both the reachability set and the antecedent set the reachability set and the antecedent set. To illustrate, for CSF4, only (4) is considered in both columns (the reachability set and the antecedent set) and, consequently, the col- 
Table 3. The initial reachability matrix.

\begin{tabular}{lccccccccccccc}
\hline CSF5 & CSF1 & CSF2 & CSF3 & CSF4 & CSF5 & CSF6 & CSF7 & CSF8 & CSF9 & CSF10 & CSF11 & CSF12 \\
\hline CSF1 & 1 & 1 & 1 & 1 & 1 & 1 & 1 & 1 & 1 & 0 & 0 & 1 \\
CSF2 & 0 & 1 & 1 & 0 & 0 & 0 & 0 & 0 & 0 & 0 & 0 & 0 \\
CSF3 & 1 & 1 & 1 & 1 & 0 & 1 & 1 & 1 & 1 & 0 & 0 & 1 \\
CSF4 & 0 & 0 & 0 & 1 & 0 & 0 & 0 & 0 & 0 & 0 & 0 & 0 \\
CSF5 & 1 & 1 & 1 & 0 & 1 & 0 & 0 & 0 & 0 & 1 & 1 & 0 \\
CSF6 & 0 & 1 & 0 & 1 & 1 & 1 & 1 & 1 & 1 & 1 & & 1 & 1 \\
CSF7 & 1 & 1 & 1 & 1 & 1 & 1 & 1 & 1 & 1 & 1 & 1 & 1 \\
CSF8 & 0 & 1 & 1 & 1 & 1 & 1 & 1 & 1 & 1 & 1 & 1 & 0 \\
CSF9 & 1 & 1 & 1 & 1 & 1 & 1 & 1 & 1 & 1 & 1 & 1 & 1 \\
CSF10 & 0 & 1 & 1 & 0 & 0 & 0 & 0 & 1 & 1 & 1 & 1 & 1 \\
CSF11 & 0 & 0 & 1 & 0 & 0 & 0 & 0 & 0 & 0 & 0 & 1 & 0 \\
CSF12 & 0 & 1 & 1 & 1 & 0 & 1 & 1 & 1 & 1 & 0 & 0 & 1 \\
\hline
\end{tabular}

Table 4. The final reachability matrix.

\begin{tabular}{ccccccccccccccc}
\hline CSF5 & CSF1 & CSF2 & CSF3 & CSF4 & CSF5 & CSF6 & CSF7 & CSF8 & CSF9 & CSF10 & CSF11 & $\begin{array}{c}\text { CSF12 } \\
\text { Driving } \\
\text { power }\end{array}$ \\
\hline CSF1 & 1 & 1 & 1 & 1 & 1 & 1 & 1 & 1 & 1 & $1^{*}$ & $1^{*}$ & 1 & 12 \\
CSF2 & $1^{*}$ & 1 & 1 & $1^{*}$ & 0 & $1^{*}$ & $1^{*}$ & $1^{*}$ & $1^{*}$ & 0 & 0 & $1^{*}$ & 9 \\
CSF3 & 1 & 1 & 1 & 1 & $1^{*}$ & 1 & 1 & 1 & 1 & $1^{*}$ & $1^{*}$ & 1 & 12 \\
CSF4 & 0 & 0 & 0 & 1 & 0 & 0 & 0 & 0 & 0 & 0 & 0 & 0 & 1 \\
CSF5 & 1 & 1 & 1 & $1^{*}$ & 1 & $1^{*}$ & $1^{*}$ & $1^{*}$ & $1^{*}$ & 1 & 1 & $1^{*}$ & 12 \\
CSF6 & $1^{*}$ & 1 & $1^{*}$ & 1 & 1 & 1 & 1 & 1 & 1 & 1 & 1 & 1 & 12 \\
CSF7 & 1 & 1 & 1 & 1 & 1 & 1 & 1 & 1 & 1 & 1 & 1 & 1 & 12 \\
CSF8 & $1^{*}$ & 1 & 1 & 1 & 1 & 1 & 1 & 1 & 1 & 1 & 1 & $1^{*}$ & 12 \\
CSF9 & 1 & 1 & 1 & 1 & 1 & 1 & 1 & 1 & 1 & 1 & 1 & 1 & 12 \\
CSF10 & $1^{*}$ & 1 & 1 & $1^{*}$ & $1^{*}$ & $1^{*}$ & $1^{*}$ & 1 & 1 & 1 & 1 & 1 & 12 \\
CSF11 & $1^{*}$ & $1^{*}$ & 1 & $1^{*}$ & 0 & $1^{*}$ & $1^{*}$ & $1^{*}$ & $1^{*}$ & 0 & 1 & $1^{*}$ & 10 \\
CSF12 & $1^{*}$ & 1 & 1 & 1 & $1^{*}$ & 1 & 1 & 1 & 1 & $1^{*}$ & $1^{*}$ & 1 & 12 \\
Dependence & 11 & 11 & 11 & 12 & 9 & 11 & 11 & 11 & 11 & 9 & 10 & 11 \\
power & 11 & & & & & & & & & & & & \\
\hline
\end{tabular}

Table 5. Levels of CSFs- $1^{\text {st }}$ iteration.

\begin{tabular}{|c|c|c|c|c|}
\hline CSFs & Reachability set & Antecedent set & Intersection & Leve \\
\hline CSF1 & $1,2,3,4,5,6,7,8,9,10,11,12$ & $1,2,3,5,6,7,8,9,10,11,12$ & $1,2,3,5,6,7,8,9,10,11,12$ & \\
\hline CSF2 & $1,2,3,4,6,7,8,9,12$ & $1,2,3,5,6,7,8,9,10,11,12$ & $1,2,3, \quad 6,7,8,9,12$ & \\
\hline CSF3 & $1,2,3,4,5,6,7,8,9,10,11,12$ & $1,2,3,5,6,7,8,9,10,11,12$ & $1,2,3,5,6,7,8,9,10,11,12$ & \\
\hline CSF4 & 4 & $1,2,3,4,5,6,7,8,9,10,11,12$ & 4 & I \\
\hline CSF5 & $1,2,3,4,5,6,7,8,9,10,11,12$ & $1,3,5,6,7,8,9,10,12$ & $1,3,5,6,7,8,9,10,12$ & \\
\hline CSF6 & $1,2,3,4,5,6,7,8,9,10,11,12$ & $1,2,3,5,6,7,8,9,10,11,12$ & $1,2,3,5,6,7,8,9,10,11,12$ & \\
\hline CSF7 & $1,2,3,4,5,6,7,8,9,10,11,12$ & $1,2,3,5,6,7,8,9,10,11,12$ & $1,2,3,5,6,7,8,9,10,11,12$ & \\
\hline CSF8 & $1,2,3,4,5,6,7,8,9,10,11,12$ & $1,2,3,5,6,7,8,9,10,11,12$ & $1,2,3,5,6,7,8,9,10,11,12$ & \\
\hline CSF9 & $1,2,3,4,5,6,7,8,9,10,11,12$ & $1,2,3,5,6,7,8,9,10,11,12$ & $1,2,3,5,6,7,8,9,10,11,12$ & \\
\hline CSF10 & $1,2,3,4,5,6,7,8,9,10,11,12$ & $1,3,5,6,7,8,9,10,12$ & $1,3,5,6,7,8,9,10,12$ & \\
\hline CSF11 & $1,2,3,4,6,7,8,9,11,12$ & $1,3,5,6,7,8,9,10,11,12$ & $1,3,6,7,8,9,11,12$ & \\
\hline CSF12 & $1,2,3,4,5,6,7,8,9,10,11,12$ & $1,2,3,5,6,7,8,9,10,11,12$ & $1,2,3,5,6,7,8,9,10,11,12$ & \\
\hline
\end{tabular}


umn of intersection for CSF4 includes 4 alone. Table 5 shows the application of this procedure to all CSFs. In order to identify the level of each CSF, any CSF that has reachability set similar to the intersection is considered within level I. As shown in Table 5, the CSF4's row is the only row that is highlighted (colored differentlylight gray) because it's reachability set as well as it's intersection set contains the same set of CSFs (in this case, only one CSF is considered which is CSF4). As a result, CSF4 is the only factor that is classified within level I. Table 6 presents the second iteration in which the second level (i.e. II) is identified. However, CSF4 should not be considered and must be removed from Table 6 because it's corresponding level is already identified in Table 5 (ignored and colored in a dark gray in Table 6). Now, it is demonstrated in Table 6 that CSFs 1, 2, 3, 6, 7, 8, 9, and 12 (colored differently-light gray) are classified in level II because, for each one of them, the reachability set is similar to the intersection. Similar procedure is applied in Table 7 and Table 8 to identify level III and level IV, respectively.

Table 6. Levels of CSFs-2 $2^{\text {nd }}$ iteration.

\begin{tabular}{ccccc}
\hline CSFs & Reachability set & Antecedent set & Intersection & Level \\
\hline CSF1 & $1,2,3,5,6,7,8,9,10,11,12$ & $1,2,3,5,6,7,8,9,10,11,12$ & $1,2,3,5,6,7,8,9,10,11,12$ & II \\
CSF2 & $1,2,3,6,7,8,9,12$ & $1,2,3,5,6,7,8,9,10,11,12$ & $1,2,3,6,7,8,9,12$ & II \\
CSF3 & $1,2,3,5,6,7,8,9,10,11,12$ & $1,2,3,5,6,7,8,9,10,11,12$ & $1,2,3,5,6,7,8,9,10,11,12$ & II \\
CSF4 & \multicolumn{1}{c}{4} & $1,2,3,4,5,6,7,8,9,10,11,12$ & I \\
CSF5 & $1,2,3,5,6,7,8,9,10,11,12$ & $1,3,5,6,7,8,9,10,12$ & $1,3,5,6,7,8,9,10,12$ \\
CSF6 & $1,2,3,5,6,7,8,9,10,11,12$ & $1,2,3,5,6,7,8,9,10,11,12$ & $1,2,3,5,6,7,8,9,10,11,12$ & II \\
CSF7 & $1,2,3,5,6,7,8,9,10,11,12$ & $1,2,3,5,6,7,8,9,10,11,12$ & $1,2,3,5,6,7,8,9,10,11,12$ & II \\
CSF8 & $1,2,3,5,6,7,8,9,10,11,12$ & $1,2,3,5,6,7,8,9,10,11,12$ & $1,2,3,5,6,7,8,9,10,11,12$ & II \\
CSF9 & $1,2,3, \quad 5,6,7,8,9,10,11,12$ & $1,2,3,5,6,7,8,9,10,11,12$ & $1,2,3,5,6,7,8,9,10,11,12$ & II \\
\hline CSF10 & $1,2,3,5,6,7,8,9,10,11,12$ & $1,3,5,6,7,8,9,10,12$ & $1,3,5,6,7,8,9,10,12$ & \\
CSF11 & $1,2,3,6,7,8,9,11,12$ & $1,3,5,6,7,8,9,10,11,12$ & $1,3,6,7,8,9,11,12$ & II \\
\hline CSF12 & $1,2,3,5,6,7,8,9,10,11,12$ & $1,2,3,5,6,7,8,9,10,11,12$ & $1,2,3,5,6,7,8,9,10,11,12$ \\
\hline
\end{tabular}

Table 7. Levels of CSFs-3 $3^{\text {rd }}$ iteration.

\begin{tabular}{|c|c|c|c|c|}
\hline CSFs & Reachability set & Antecedent set & Intersection & Level \\
\hline CSF1 & $1,2,3,5,6,7,8,9,10,11,12$ & $1,2,3,5,6,7,8,9,10,11,12$ & $1,2,3,5,6,7,8,9,10,11,12$ & II \\
\hline CSF2 & $1,2,3,6,7,8,9,12$ & $1,2,3,5,6,7,8,9,10,11,12$ & $1,2,3,6,7,8,9,12$ & II \\
\hline CSF3 & $1,2,3,5,6,7,8,9,10,11,12$ & $1,2,3,5,6,7,8,9,10,11,12$ & $1,2,3,5,6,7,8,9,10,11,12$ & II \\
\hline CSF4 & 4 & $1,2,3,4,5,6,7,8,9,10,11,12$ & 4 & I \\
\hline CSF5 & $5,10,11$ & 5,10 & 5,10 & \\
\hline CSF6 & $1,2,3,5,6,7,8,9,10,11,12$ & $1,2,3,5,6,7,8,9,10,11,12$ & $1,2,3,5,6,7,8,9,10,11,12$ & II \\
\hline CSF7 & $1,2,3,5,6,7,8,9,10,11,12$ & $1,2,3,5,6,7,8,9,10,11,12$ & $1,2,3,5,6,7,8,9,10,11,12$ & II \\
\hline CSF8 & $1,2,3,5,6,7,8,9,10,11,12$ & $1,2,3,5,6,7,8,9,10,11,12$ & $1,2,3,5,6,7,8,9,10,11,12$ & II \\
\hline CSF9 & $1,2,3,5,6,7,8,9,10,11,12$ & $1,2,3,5,6,7,8,9,10,11,12$ & $1,2,3,5,6,7,8,9,10,11,12$ & II \\
\hline CSF10 & $5,10,11$ & 5,10 & 5,10 & \\
\hline CSF11 & 11 & 11 & 11 & III \\
\hline CSF12 & $1,2,3,5,6,7,8,9,10,11,12$ & $1,2,3,5,6,7,8,9,10,11,12$ & $1,2,3,5,6,7,8,9,10,11,12$ & II \\
\hline
\end{tabular}


Table 8. Levels of CSFs- $4^{\text {th }}$ iteration.

\begin{tabular}{ccccc}
\hline CSFs & Reachability set & Antecedent set & Intersection & Level \\
\hline CSF1 & $1,2,3,5,6,7,8,9,10,11,12$ & $1,2,3,5,6,7,8,9,10,11,12$ & $1,2,3,5,6,7,8,9,10,11,12$ & II \\
CSF2 & $1,2,3,6,7,8,9,12$ & $1,2,3,5,6,7,8,9,10,11,12$ & $1,2,3,6,7,8,9,12$ & II \\
CSF3 & $1,2,3,5,6,7,8,9,10,11,12$ & $1,2,3,5,6,7,8,9,10,11,12$ & $1,2,3,5,6,7,8,9,10,11,12$ & II \\
CSF4 & 4 & $1,2,3,4,5,6,7,8,9,10,11,12$ & 4 & I \\
CSF5 & 5,10, & 5,10 & 5,10 & IV \\
CSF6 & $1,2,3,5,6,7,8,9,10,11,12$ & $1,2,3,5,6,7,8,9,10,11,12$ & $1,2,3,5,6,7,8,9,10,11,12$ & II \\
CSF7 & $1,2,3,5,6,7,8,9,10,11,12$ & $1,2,3,5,6,7,8,9,10,11,12$ & $1,2,3,5,6,7,8,9,10,11,12$ & II \\
CSF8 & $1,2,3,5,6,7,8,9,10,11,12$ & $1,2,3,5,6,7,8,9,10,11,12$ & $1,2,3,5,6,7,8,9,10,11,12$ & II \\
CSF9 & $1,2,3,5,6,7,8,9,10,11,12$ & $1,2,3,5,6,7,8,9,10,11,12$ & $1,2,3,5,6,7,8,9,10,11,12$ & II \\
CSF10 & 5,10, & 5,10 & 5,10 & IV \\
CSF11 & 1, & 11 & 11 & III \\
CSF12 & $1,2,3,5,6,7,8,9,10,11,12$ & $1,2,3,5,6,7,8,9,10,11,12$ & $1,2,3,5,6,7,8,9,10,11,12$ & II \\
\hline
\end{tabular}

\section{Discussion}

One of the main purposes of any ISM application is to classify the investigated elements, according to their driver and dependence power, into one of the four clusters (zones), namely: independent variables (drivers), dependent variables, linkage variables, and autonomous variables. independent variables category contains all variables that have a strong driving power associated with weak dependence power while, in contrast, dependent variables category contains all variables that have a strong dependence power associated with weak driving power. Linkage variables category includes all variables that have a strong dependence and driving power while Autonomous variables category is characterized by variables with weak dependence and driving power. Such a categorization helps to obtain a more detailed picture for the CSFs in order to interpret the interaction among them clearly and in a more logical approach.

Figure 1 shows that none of the CSFs is located in the autonomous category which indicates that, in general, all CSFs are depending on each other. Such a result also confirms the results of the previous studies in the literature, that is, all these twelve factors are critical for six sigma implementation. More specifically, Figure 1 shows that all CSFs, except CSF4 (organizational infrastructure and culture), are classified as linkage variables, which implies that the interaction among these factors plays a significant role in implementing six sigma. The absence of CSFs in the independent zone confirms this fact. However, within the linkage zone, CSF5 (education and training) and CSF10 (understanding tools and techniques within six sigma) are relatively more independent, which reveals sort of dominance over other linkage CSFs. This is reasonably accepted due to the fact that these two CSFs have the lowest dependence power values among all CSFs (see Table 4). Such a fact reveals that, as illustrated in Figure 2, providing the theoretical training for six sigma implementation must be subjected to providing the required knowledge related to the tools and techniques for six sigma. Moreover, implementing both of them (CSF5 and CSF10) should be followed by the practical application of six sigma in order to refine the required skills of project management (CSF11). Figure 2 demonstrates the interaction among all CSFs with respect to the corresponding level of each CSF (as illustrated in Table 5 to Table 8) and, consequently, priorities of CSFs are identified. To illustrate, CSF5 (education and training) and CSF10 (understanding tools and techniques within six sigma) are located in the bottom of the ISM model, which reflect that these two CSFs represent the base of six sigma implementation (1st priority). In contrast, CSF4 (Organizational infrastructure and culture) is located in the top of the developed model to reflect the fact that this CSF is resulting of implementing all other CSFs (lowest priority in term of implementation). Therefore, as shown also in Figure 1, CSF4 is located lonely in the zone of dependent variables which reveals that the implementation of this factor is a result of implementing all other CSFs. In other words, achieving appropriate organizational infrastructure and culture for six sigma is a consequence of practicing all other CSFs. 


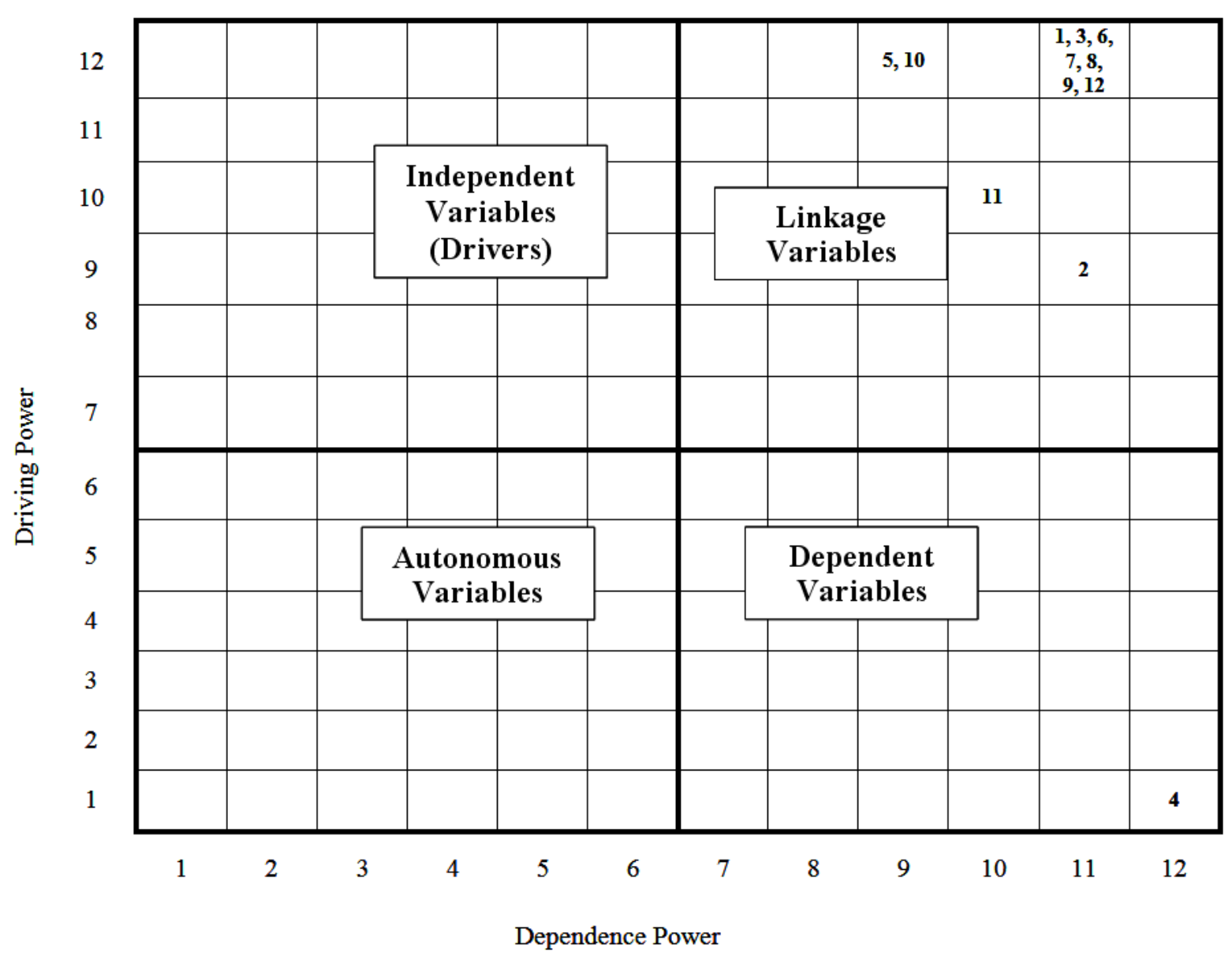

Figure 1. Clusters of CSFs.

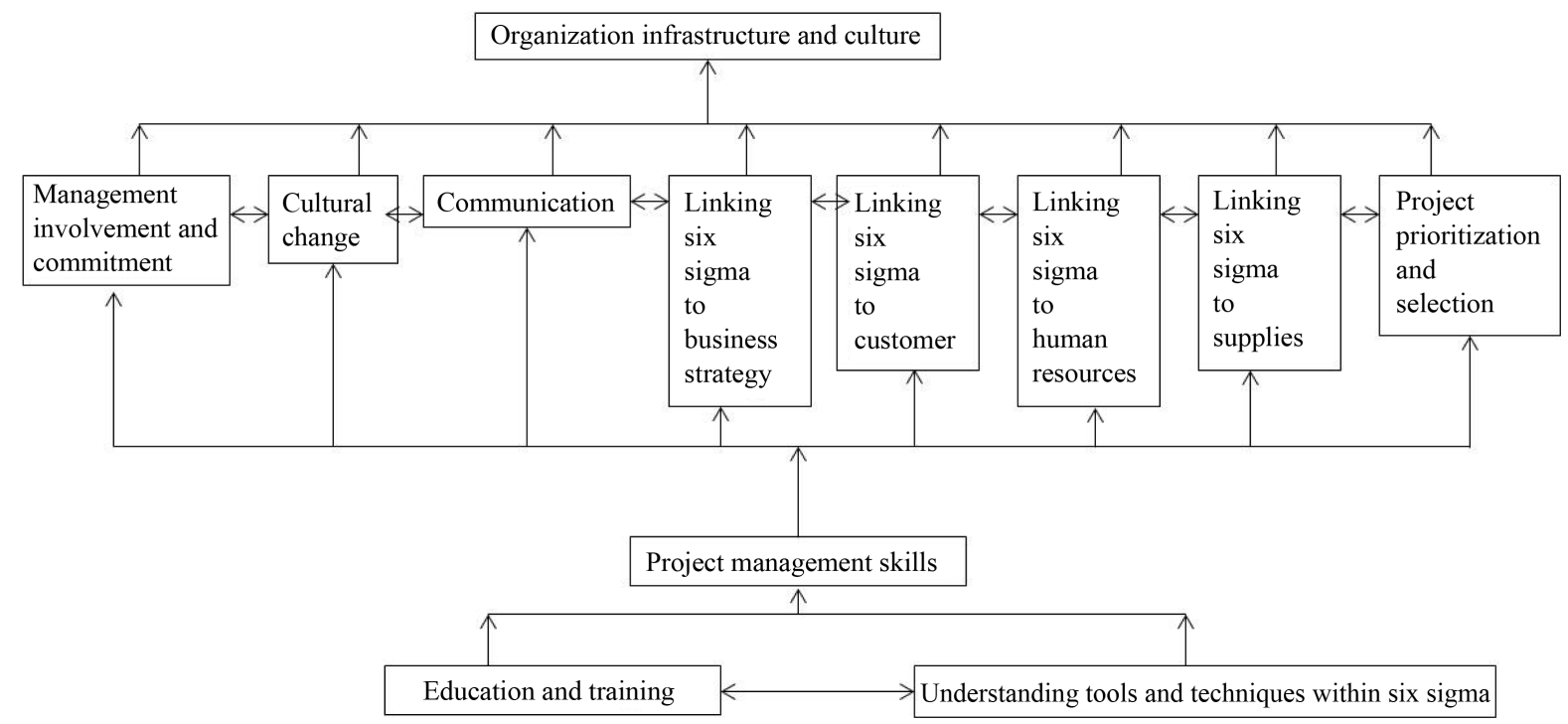

Figure 2. The final diagraph of the CSFs (i.e. the developed ISM).

\section{Conclusion}

In this paper, CSFs for six sigma implementation were investigated through the developed ISM model. The de- 
veloped model provides a road map that assists the practitioners to understand the process through which six sigma is practiced in a certain enterprise. However, one cannot generalize such a result within the automotive service industry although it gives insight on how SCFs are interacting in one of the largest automotive service providers in Saudi Arabia. Practices of six sigma implementation are still in need to be critically investigated independently (i.e. case studies). A single firm may have its own approach of implementing and practicing six sigma. However, even though the studied case was selected from the automotive service industry, the outcome of this study supports the results of previous empirical studies in a sense that all factors for six sigma implementation are, in fact, critical (i.e. none of them is located within the autonomous category). Nevertheless, there is still a room for statistical validation. Specifically, the developed ISM model is in need of statistical validation that can be conducted using the Structural Equation Modeling (SEM). ISM can be employed to represent theoretical platform on which SEM can be implemented in a more confident manner. Such a recommendation has also been proposed by Singh and Kant [27]. Finally, this paper provides ISM as a mathematical (soft operational research) tool that enables firms and practitioners to precisely understand their practice of six sigma implementation, which in turn opens the door for further investigations.

\section{Acknowledgements}

The author would like to thank King Abdulaziz University (KAU), Jeddah, Saudi Arabia, for providing the required support in order to conduct and publish this paper. The author also would like to thank Mr. Saleh Mahjoub, Mr. Rakan Maghrabi, and Mr. Faisal Almarwani for their efforts in collecting data.

\section{References}

[1] Raisinghani, M.S., Ette, H., Pierce, R., Cannon, G. and Daripaly, P. (2005) Six Sigma: Concepts, Tools, and Applications. Industrial Management \& Data Systems, 105, 491-505. http://dx.doi.org/10.1108/02635570510592389

[2] Snee, R.D. (2004) Six-Sigma: The Evolution of 100 Years of Business Improvement Methodology. International Journal of Six Sigma and Competitive Advantage, 1, 4-20. http://dx.doi.org/10.1504/IJSSCA.2004.005274

[3] Antony, J., Kumar, M. and Madu, C.N. (2005) Six Sigma in Small- and Medium-Sized UK Manufacturing Enterprises: Some Empirical Observations. International Journal of Quality \& Reliability Management, 22, 860-874. http://dx.doi.org/10.1108/02656710510617265

[4] Kumar, M., Antony, J., Singh, R.K., Tiwari, M.K. and Perry, D. (2006) Implementing the Lean Sigma Framework in an Indian SME: A Case Study. Production Planning and Control, 17, 407-423. http://dx.doi.org/10.1080/09537280500483350

[5] Antony, J. (2007) Is Six Sigma a Management Fad or Fact? Assembly Automation, 27, 17-19. http://dx.doi.org/10.1108/01445150710724658

[6] Mayor, T. (2004) Six Sigma Comes to IT Targeting Perfection. CIO Magazine, 3, 12-16.

[7] Henderson, K.M. and Evans, J.R. (2000) Successful Implementation of Six Sigma: Benchmarking General Electric Company. Benchmarking: An International Journal, 7, 260-282. http://dx.doi.org/10.1108/14635770010378909

[8] Antony, J. and Banuelas, R. (2002) Key Ingredients for the Effective Implementation of Six Sigma Program. Measuring Business Excellence, 6, 20-27. http://dx.doi.org/10.1108/13683040210451679

[9] Coronado, R.B. and Antony, J. (2002) Critical Success Factors for the Successful Implementation of Six Sigma Projects in Organizations. The TQM Magazine, 14, 92-99. http://dx.doi.org/10.1108/09544780210416702

[10] Starbird, C.D. (2002) Business Excellence: Six Sigma as a Management System. Annual Quality Congress Proceedings-American Society for Quality Control, ASQ, 47-56.

[11] Johnson, A. and Swisher, B. (2003) How Six Sigma Improves R\&D. Research Technology Management, 46, 12-15.

[12] Kwak, Y.H. and Anbari, F.T. (2006) Benefits, Obstacles, and Future of Six Sigma Approach. Technovation, 26, 708715. http://dx.doi.org/10.1016/j.technovation.2004.10.003

[13] Brun, A. (2011) Critical Success Factors of Six Sigma Implementations in Italian Companies. International Journal of Production Economics, 131, 158-164. http://dx.doi.org/10.1016/j.ijpe.2010.05.008

[14] Rockart, J.F. (1979) Chief Executives Define Their Own Data Needs. Harvard Business Review, 57, 81-93.

[15] Zu, X., Robbins, T.L. and Fredendall, L.D. (2010) Mapping the Critical Links between Organizational Culture and TQM/Six Sigma Practices. International Journal of Production Economics, 123, 86-106. http://dx.doi.org/10.1016/j.ijpe.2009.07.009

[16] Kanungo, S. and Bhatnagar, V.V. (2002) Beyond Generic Models for Information System Quality: The Use of Inter- 
pretive Structural Modeling (ISM). Systems Research and Behavioral Science, 19, 531-549.

http://dx.doi.org/10.1002/sres.476

[17] Harary, F.N.R. and Cartwright, D. (1965) Structural Models: An Introduction to the Theory of Directed Graphs. Wiley, New York.

[18] Waller, R.J. (1980) Contextual Relations and Mathematical Relations in Interpretive Structural Modeling. IEEE Transactions on Systems, Man and Cybernetics, 10, 143-145. http://dx.doi.org/10.1109/TSMC.1980.4308451

[19] Ohuchi, A., Kurihara, M. and Kaji, I. (1986) Implication Theory and Algorithm for Reachability Matrix Model. IEEE Transactions on Systems, Man and Cybernetics, 16, 610-616. http://dx.doi.org/10.1109/TSMC.1986.289267

[20] Warfield, J.N. (1973) An Assault on Complexity. Battelle Memorial Institute, Columbus.

[21] Kanungo, S. (2005) Using Process Theory to Analyze Direct and Indirect Value-Drivers of Information Systems. HICSS'05. Proceedings of the 38th Annual Hawaii International Conference on System Sciences, 3-6 January 2005, 231c.

[22] Anantatmula, V. and Kanungo, S. (2008) Role of IT and KM in Improving Project Management Performance. VINE, 38, 357-369. http://dx.doi.org/10.1108/03055720810904862

[23] Faisal, M.N. (2010) Sustainable Supply Chains: A Study of Interaction among the Enablers. Business Process Management Journal, 16, 508-529. http://dx.doi.org/10.1108/14637151011049476

[24] Mandal, A. and Deshmukh, S.G. (1994) Vendor Selection Using Interpretive Structural Modelling (ISM). International Journal of Operations \& Production Management, 14, 52-59. http://dx.doi.org/10.1108/01443579410062086

[25] Jharkharia, S. and Shankar, R. (2004) IT Enablement of Supply Chains: Modeling the Enablers. International Journal of Productivity and Performance Management, 53, 700-712. http://dx.doi.org/10.1108/17410400410569116

[26] Thakkar, J., Deshmukh, S.G., Gupta, A.D. and Shankar, R. (2006) Development of a Balanced Scorecard: An Integrated Approach of Interpretive Structural Modeling (ISM) and Analytic Network Process (ANP). International Journal of Productivity and Performance Management, 56, 25-59. http://dx.doi.org/10.1108/17410400710717073

[27] Singh, M.D. and Kant, R. (2008) Knowledge Management Barriers: An Interpretive Structural Modeling Approach. International Journal of Management Science and Engineering Management, 3, 141-150.

[28] Kannan, G., Haq, A.N., Sasikumar, P. and Arunachalam, S. (2008) Analysis and Selection of Green Suppliers Using Interpretative Structural Modelling and Analytic Hierarchy Process. International Journal of Management and Decision Making, 9, 163-182. http://dx.doi.org/10.1504/IJMDM.2008.017198

[29] Soti, A., Shankar, R. and Kaushal, O.P. (2010) Modeling the Enablers of Six Sigma Using Interpreting Structural Modeling. Journal of Modelling in Management, 5, 124-141. http://dx.doi.org/10.1108/17465661011060989

[30] Singh, A.K. (2013) Modeling Enablers of TQM to Improve Airline Performance. International Journal of Productivity and Performance Management, 62, 250-275. http://dx.doi.org/10.1108/17410401311309177

[31] Tripathy, S., Sahu, S. and Ray, P.K. (2013) Interpretive Structural Modelling for Critical Success Factors of R\&D Performance in Indian Manufacturing Firms. Journal of Modelling in Management, 8, 212-240. http://dx.doi.org/10.1108/JM2-11-2011-0061

[32] Raeesi, R., Dastrang, M., Mohammadi, S. and Rasouli, E. (2013) Understanding the Interactions among the Barriers to Entrepreneurship Using Interpretive Structural Modeling. International Journal of Business and Management, 8, 56. http://dx.doi.org/10.5539/ijbm.v8n13p56

[33] Ansari, M.F., Kharb, R.K., Luthra, S., Shimmi, S.L. and Chatterji, S. (2013) Analysis of Barriers to Implement Solar Power Installations in India Using Interpretive Structural Modeling Technique. Renewable and Sustainable Energy Reviews, 27, 163-174. http://dx.doi.org/10.1016/j.rser.2013.07.002

[34] Gorane, S.J. and Kant, R. (2013) Modelling the SCM Enablers: An Integrated ISM-Fuzzy MICMAC Approach. Asia Pacific Journal of Marketing and Logistics, 25, 263-286. http://dx.doi.org/10.1108/13555851311314059

[35] Mathiyazhagan, K. and Haq, A.N. (2013) Analysis of the Influential Pressures for Green Supply Chain Management Adoption-An Indian Perspective Using Interpretive Structural Modeling. The International Journal of Advanced Manufacturing Technology, 68, 817-833.

[36] Kumar, S., Luthra, S. and Haleem, A. (2013) Customer Involvement in Greening the Supply Chain: An Interpretive Structural Modeling Methodology. Journal of Industrial Engineering International, 9, 6. http://dx.doi.org/10.1186/2251-712X-9-6

[37] Govindan, K., Kannan, D., Mathiyazhagan, K., Jabbour, A.B.L.D.S. and Jabbour, C.J.C. (2013) Analysing Green Supply Chain Management Practices in Brazil’s Electrical/Electronics Industry Using Interpretive Structural Modelling. International Journal of Environmental Studies, 70, 477-493.

[38] Li, T.B. and Li, S.D. (2013) Application of ISM in Influence Factors of Human Resource Training Effects of Trans- 
portation Enterprises. In: The 19th International Conference on Industrial Engineering and Engineering Management, Springer, Berlin Heidelberg, 845-852.

[39] Azevedo, S., Carvalho, H. and Cruz-Machado, V. (2013) Using Interpretive Structural Modelling to Identify and Rank Performance Measures: An Application in the Automotive Supply Chain. Baltic Journal of Management, 8, 208-230. http://dx.doi.org/10.1108/17465261311310027

[40] Mehta, N., Verma, P. and Seth, N. (2013) Total Quality Management Implementation in Engineering Education in India: An Interpretive Structural Modelling Approach. Total Quality Management \& Business Excellence, 25, 124-140. 
Scientific Research Publishing (SCIRP) is one of the largest Open Access journal publishers. It is currently publishing more than 200 open access, online, peer-reviewed journals covering a wide range of academic disciplines. SCIRP serves the worldwide academic communities and contributes to the progress and application of science with its publication.

Other selected journals from SCIRP are listed as below. Submit your manuscript to us via either submit@scirp.org or Online Submission Portal.
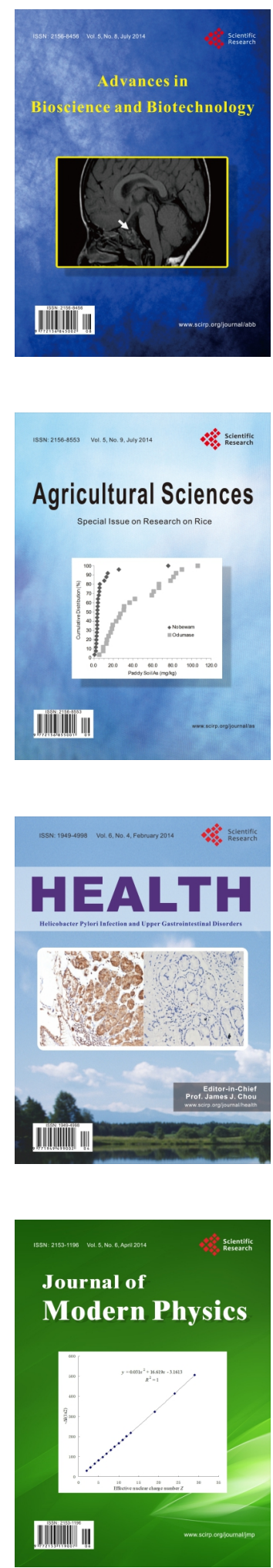
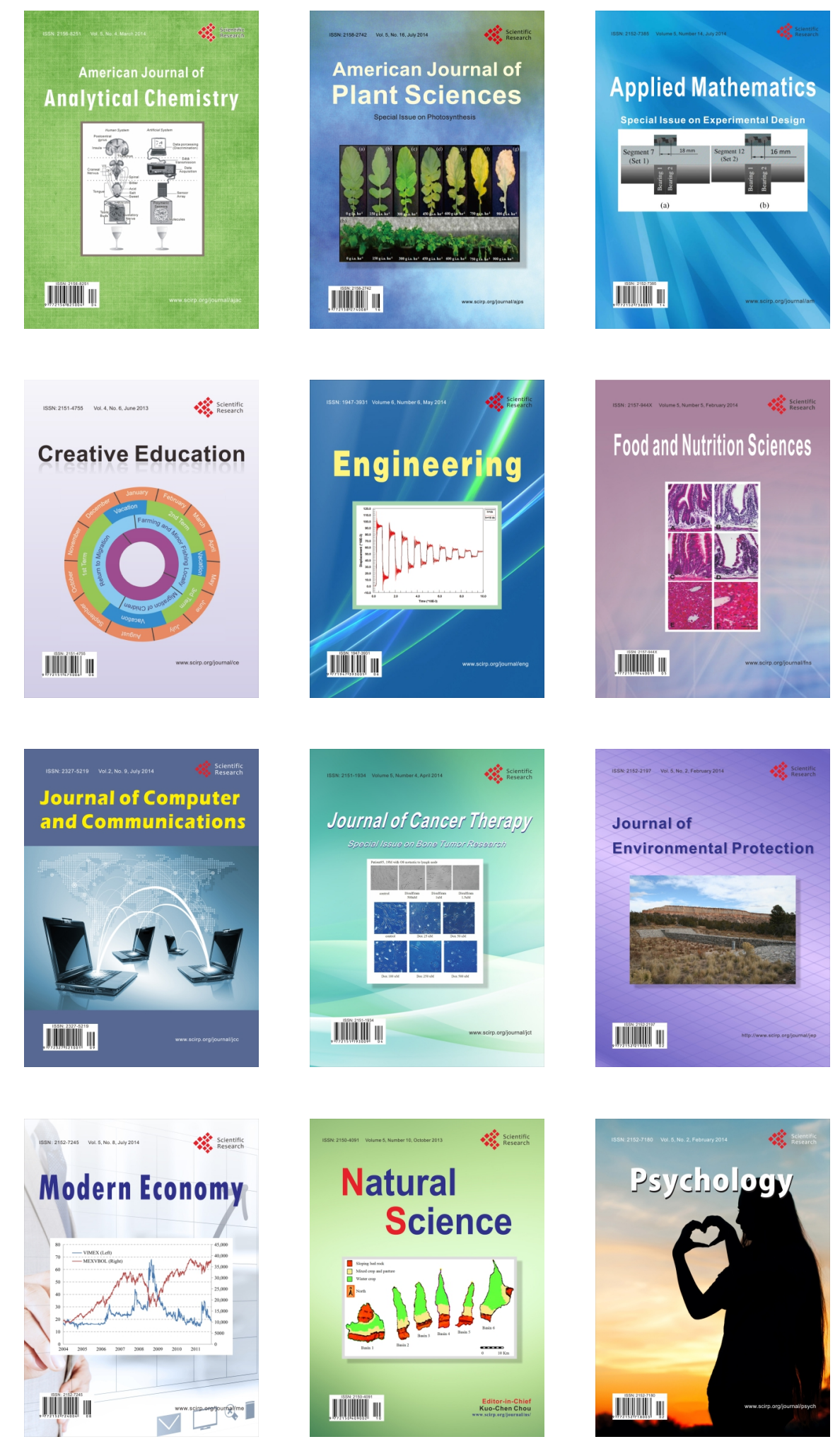